\title{
Thioether excretion in urine of applicators exposed to 1,3-dichloropropene: a comparison with urinary mercapturic acid excretion
}

\section{Abstract}

The excretion of thioethers in urine of applicators occupationally exposed to the soil fumigant 1,3-dichloropropene (DCP) was determined by the thioether assay. The mercapturic acid metabolite of E-1,3dichloropropene, $\mathbf{N}$-acetyl-S-(E-3-chloropropenyl-2-)-L-cysteine (E-DCP-MA), was the reference compound in the thioether assay. The mean recovery of E-DCP-MA was $58.5 \%$ (coefficient of variation (CV) $9 \%, n=4)$. In non-exposed men mean background of urinary thioethers was $6.05 \mathrm{mmol} \mathrm{SH} / \mathrm{mol}$ creatinine $(n=56)$. In applicators exposed to soil fumigants containing DCP, urinary excretion of thioethers followed first order elimination kinetics. Urinary half lives of elimination of thioethers were 8.0 (SD 2.5) hours based on excretion rates and 9.5 (SD 3.1) hours based on creatinine excretion. The urinary half life of elimination of thioethers was almost twofold higher compared with half lives of elimination of the mercapturic acids of $Z$ - and E-1,3dichloropropene. The post- minus pre-shift thioether concentrations in urine and the cumulative urinary thioether excretions correlated well with exposure to DCP. In urine samples the mean thioether concentration was 1.38 higher than mean DCP mercapturic acid concentration. This suggests the presence of unidentified thioether metabolite(s) due to exposure to soil fumigants containing DCP. According to the present data, an eight hour time weighted average exposure to the Dutch occupational exposure limit of $5 \mathrm{mg} / \mathrm{m}^{3}$ DCP

Department of Pharmacochemistry, Division of Molecular Toxicology, Free University, De Boelelaan 1083, 1081 HV Amsterdam, The Netherlands

R T H van Welie, N P E Vermeulen

Department of Human Toxicology, University Hospital of Leiden, Leiden, The Netherlands

C M van Marrewijk, F A de Wolff results in a post- minus pre-shift thioether concentration of $9.6 \mathrm{mmol} \mathrm{SH} / \mathrm{mol}$ creatinine (95\% confidence interval $(95 \% \mathrm{CI}) \quad 7 \cdot 4-$ $11.8 \mathrm{mmol} \mathrm{SH} / \mathrm{mol}$ creatinine) and in a cumulative thioether excretion of $139 \mu \mathrm{mol} \mathrm{SH}$ (95\% CI 120-157 $\mu \mathrm{mol} \mathrm{SH).} \mathrm{It} \mathrm{is} \mathrm{concluded} \mathrm{that}$ the thioether assay can be used to assess comparatively high levels of exposure to DCP.

Exposure of man to electrophilic compounds may ultimately lead to the excretion of thioethers such as cysteine conjugates and mercapturic acids ( $\mathrm{S}$-substituted $\mathrm{N}$-acetyl-L-cysteine conjugates) in urine. Mercapturic acids are end products from metabolic detoxication of electrophilic chemicals via conjugation to glutathione. Glutathione conjugation either proceeds spontaneously or is catalysed by glutathione S-transferases present in liver, blood, and several other organs and tissues. Once glutathione conjugates have been formed in vivo, metabolic cleavage of the glutamyl and glycine residue generally takes place. $\mathrm{N}$-acetylation of the remaining $\mathrm{S}$ alkylated cysteine conjugates finally leads to the formation of the mercapturic acid.

Mercapturic acids excreted in urine can be determined as thioethers using the thioether assay. The determination of urinary thioethers can be used as a non-selective test to assess exposure to electrophilic compounds. ${ }^{1}$ The thioether assay has been used frequently to compare exposed and non-exposed populations, for example, factories producing rubber, ${ }^{2}$ pharmaceuticals and explosives, or upon exposure to bitumen fumes. ${ }^{34}$ Mostly, however, no information is available about the chemical structure of the various thioethers determined. Besides a limited selectivity, the sensitivity of the thioether assay is also limited by background excretion of thioethers. This is strongly influenced by lifestyle factors (for instance, smoking and medication). By contrast, for the determination of mercapturic acids in urine, selective and sensitive analytical techniques such as high performance liquid chromatography and gas chromatography with different detection techniques are available. ${ }^{56}$

Recently, occupational exposure to Z- and E-1,3- 
dichloropropene (Z- and E-DCP) of applicators in the Dutch flower bulb culture was determined and shown to result in urinary excretion of two mercapturic acids-namely, N-acetyl-S-(Z- and E-3chloropropenyl-2-)-L-cysteine (Z- and E-DCP$M A)$. A linear relation between exposure to $Z$ - and $E$ DCP and excretion of Z- and E-DCP-MA in urine was found. Urinary half lives of elimination were 5.0 (SD 1.2) hours for Z-DCP-MA and 4.7 (SD 1.3) hours for E-DCP-MA.?

The primary aim of our study was to determine the relation between exposure to soil fumigants containing DCP and urinary excretion of thioethers in occupationally exposed applicators. The post-minus pre-shift thioether concentrations and cumulative thioether excretion were correlated with exposure to DCP. Half lives of elimination of thioethers in urine were also determined. Finally, excretion of thioether was compared with urinary mercapturic acid excretion.?

\section{Materials and methods \\ CHEMICALS}

N-acetyl-S-(Z- and E-3-chloropropenyl-2-)L-cysteine were synthesised. ${ }^{8}$ Potassium dihydrogen phosphate and citric acid (trisodium salt dihydrate) were purchased from Merck (Darmstadt, Germany). 5,-5'-Dithiobis-2-nitrobenzoic acid and creatinine stock solutions were obtained from Sigma (St Louis, MO, USA). N-acetyl-L-cysteine was purchased from Janssen Chimica (Beerse, Belgium).

\section{POPULATION AND EXPOSURE}

The population under investigation consisted of 12 male Dutch applicators of Z- and E-DCP in the flower bulb culture and four male non-exposed volunteers. The respiratory exposure to $Z$ - and EDCP of these applicators has been the subject of a combined biological, environmental, and biological effect monitoring study. ${ }^{7910}$ Population characteristics, application techniques, and sampling strategies of urine and air samples have been described extensively in these papers. Briefly, the eight hour time weighted average (TWA) exposures to $Z$ - and E-DCP were determined by means of personal air sampling during full period consecutive sampling. The exposure to $(Z+E)-D C P$ ranged from $0 \cdot 3$ to $18.9 \mathrm{mg} / \mathrm{m}^{3}$ in shifts of one to 11 hours. The urinary excretion of the corresponding mercapturic acids, Z- and E-DCP-MA, was determined in samples collected before, during, and after the exposure measurements. Mean urinary half lives of elimination were 5.0 (SD 1.2) hours for Z-DCP-MA and 4.7 (SD 1.3) hours for E-DCP-MA. Maximum cumulative urinary excretion of $(Z+E)-D C P-M A$ amounted to $296 \mu \mathrm{mol}$. Strong correlations $(r \geq 0.93)$ between exposure to Z- and E-DCP and the excre- tion of respective mercapturic acids in urine were found. $^{7}$

\section{ANALYSIS OF THIOETHERS}

The urinary excretion of thioethers was determined as described previously with slight modifications. ${ }^{11}$ Samples of human urine were centrifuged for five minutes at $4000 \mathrm{~g}$ and $2 \mathrm{ml}$ portions were transferred into glass stoppered tubes. The $\mathrm{pH}$ was adjusted to 1.5-2.0 with $0.25 \mathrm{ml} 4 \mathrm{M}$ hydrochloric acid. Two $\times$ $4 \mathrm{ml}$ of ethyl acetate were used for extraction of the acidified urine samples by vortex mixing for 30 seconds. The organic layers were separated by centrifugation for five minutes at $4000 \mathrm{~g}$ and evaporated to dryness at $37^{\circ} \mathrm{C}$ under a mild nitrogen flow. The residues obtained were resuspended in $1 \mathrm{ml}$ distilled water. Subsequently alkaline hydrolysis was performed on $0.5 \mathrm{ml}$ portions in screw capped glass tubes by adding $0.25 \mathrm{ml} 4 \mathrm{M}$ sodium hydroxide, saturating with nitrogen, and heating at $100^{\circ} \mathrm{C}$ in a boiling water bath in the dark. After hydrolysing for 50 minutes, samples were cooled on ice for 10 minutes and $0.25 \mathrm{ml}$ of $4 \mathrm{M}$ hydrochloric acid was added. To the remaining, non-hydrolysed portions of $0.5 \mathrm{ml}$ of resuspended residue, $0.5 \mathrm{ml} 4 \mathrm{M}$ sodium chloride was added.

After exactly five minutes, the sulphydryl ( $\mathrm{SH}$ ) concentrations in the hydrolysed and nonhydrolysed samples were determined by adding Ellman reagent and measuring the absorbance at $412 \mathrm{~nm}$. Freshly prepared Ellman reagent consisted of $1.0 \mathrm{ml} 1.0 \mathrm{M}$ phosphate buffer $(\mathrm{pH} 7 \cdot 1)$ and

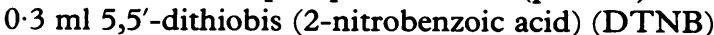
solution ( $0.4 \mathrm{mg}$ DTNB per $\mathrm{ml} 1 \%$ sodium citrate). ${ }^{12}$

Standard calibration curves of SH groups were prepared by dissolving $\mathrm{N}$-acetyl-L-cysteine in concentrations ranging from $0 \cdot 10$ to $0.80 \mathrm{mmol} / 1$ in $2 \mathrm{M}$ sodium chloride and directly analysing with Ellman reagent. Calibration curves of thioethers were prepared by dissolving $\mathrm{N}$-acetyl-S-(E-3chloropropenyl-2-)-L-cysteine (E-DCP-MA) in concentrations ranging from $0 \cdot 10$ to $0.80 \mathrm{mmol} / 1$ in human urine, and treating as described above. Both types of calibration curve were prepared fresh daily.

Urinary thioether concentrations were calculated using differences in absorbance at $412 \mathrm{~nm}$ between the hydrolysed and the non-hydrolysed parts of the samples in the regression equation of the calibration curve of E-DCP-MA. The recovery of E-DCP-MA was calculated from the ratios of the absorbance at $412 \mathrm{~nm}$ of E-DCP-MA $v$ the absorbance at $412 \mathrm{~nm}$ of the equimolar $\mathrm{SH}$ concentrations of $\mathrm{N}$-acetyl-Lcysteine.

\section{ANALYSIS OF CREATININE}

Urinary creatinine was determined by the Jaffe reaction. ${ }^{13}$ 
Table 1 Concentration dependent within day and day to day variation in recovery of $E-D C P-M A$ in thioether assay

\begin{tabular}{|c|c|c|c|c|c|c|}
\hline \multirow[b]{2}{*}{$E-D C P-M A(\mathrm{mmol} / \mathrm{l})$} & \multicolumn{3}{|l|}{ Within day } & \multicolumn{3}{|l|}{ Day to day } \\
\hline & Recovery (\%) & $C V(\%)$ & No & Recovery (\%) & $C V(\%)$ & No \\
\hline $\begin{array}{l}0.10 \\
0.20 \\
0 \cdot 40 \\
0.53 \\
0 \cdot 80 \\
\text { Mean }\end{array}$ & $\begin{array}{l}52.7 \\
58.5 \\
65.5 \\
{ }^{\star} \\
57.1 \\
58.5\end{array}$ & $\begin{array}{l}2 \cdot 5 \\
6 \cdot 6 \\
2 \cdot 3 \\
3.9 \\
9 \cdot 0\end{array}$ & $\begin{array}{l}3 \\
3 \\
3 \\
3\end{array}$ & $\begin{array}{l}58 \cdot 8 \\
60 \cdot 9 \\
65 \cdot 1 \\
70 \cdot 2 \\
50 \cdot 5 \\
61 \cdot 1\end{array}$ & $\begin{array}{r}28.5 \\
17 \cdot 8 \\
11 \cdot 7 \\
9.3 \\
6 \cdot 4 \\
12.0\end{array}$ & $\begin{array}{l}25 \\
25 \\
25 \\
14 \\
11\end{array}$ \\
\hline
\end{tabular}

^Not determined.

CALCULATIONS

Urinary elimination rate constants $\left(k_{\mathrm{el}}\right)$ of the thioethers were calculated by linear regression analysis from the linear parts of the semilogarithmic thioether excretion rate $v$ time curves or from the thioether excretion expressed per mol creatinine $v$ time curves. Elimination rate constants were used to calculate half lives of elimination $\left(t_{1 / 2}=\ln 2 / k_{e l}\right)$. Correlation coefficients ( $r$ ) were calculated as a measure for the strength of linear relations. Spearman correlations (p) were calculated to test for the significance of the correlation coefficients. Levels of significance between urinary half lives of elimination of mercapturic acids of DCP and thioethers were assessed by the two tailed Wilcoxon signed rank test.

\section{Results}

ANALYSIS OF THIOETHERS

Both types of standard calibration curves, N-acetyl1-cysteine in $2 \mathrm{M}$ sodium chloride and E-DCP-MA in human urine, showed linear relations $(r \geq 0.998 ; n$ $=25$ ). Table 1 presents within day and day to day recoveries of E-DCP-MA determined with the thioether assay. The mean within day recovery of E-DCP-MA in concentrations ranging from 0.10 to $0.80 \mathrm{mmol} / \mathrm{l}$ was $58.5 \%$ (coefficient of variation (CV) $=9 \%, n=4)$. The $C V$ was $\leq 6.6 \%$ for all E-DCP-MA concentrations tested. Mean day to day recovery was $61 \cdot 1 \%(\mathrm{CV}=12 \cdot 0 \%, \mathrm{n}=5)$. Mean within day and mean day to day recoveries were not significantly different. The day to day $\mathrm{CV}$ increased

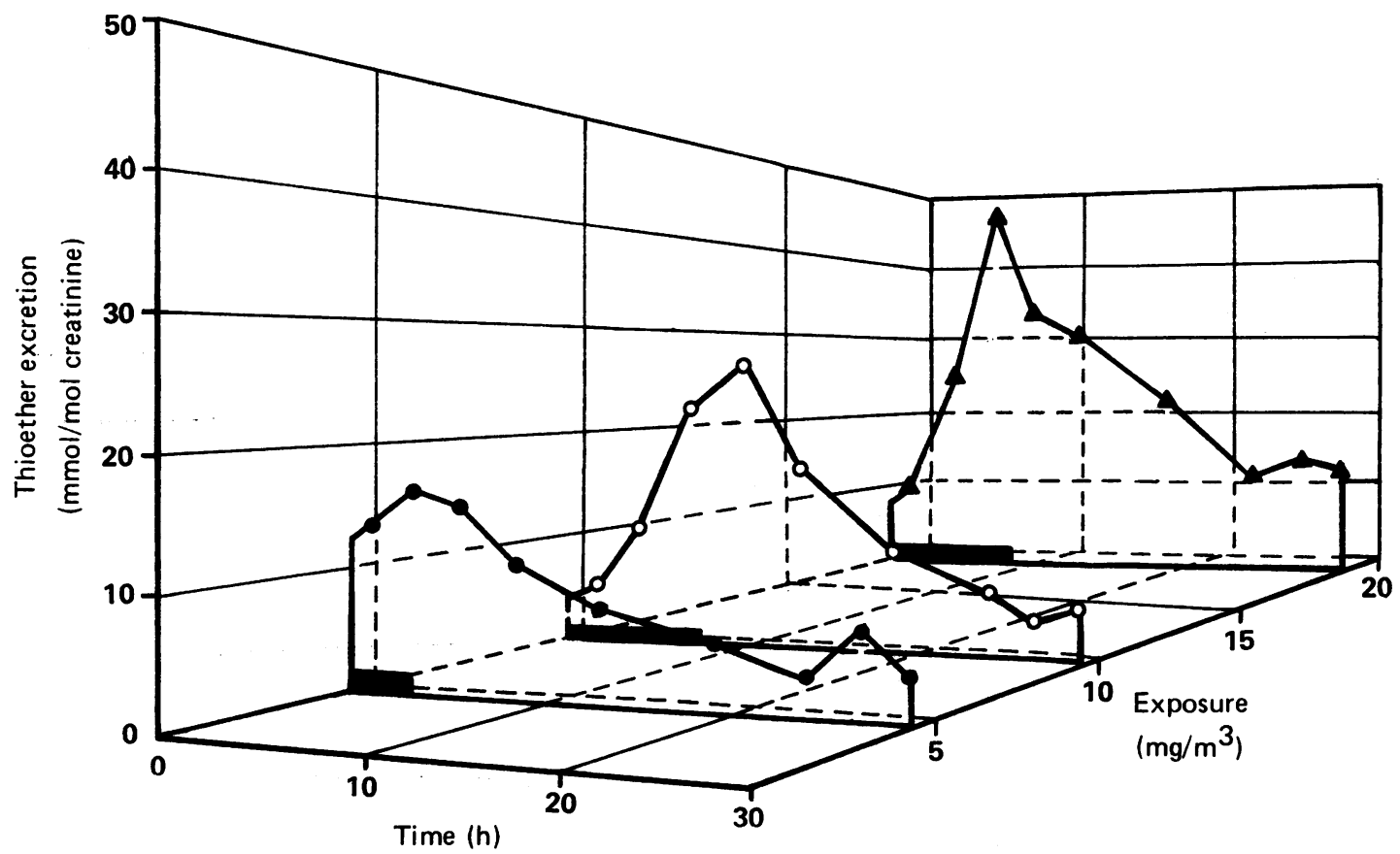

Figure 1 Urinary excretion of thioethers (per mol creatinine) of applicators exposed to 3.8 (O), 9.8 (O), and 18.9 ( $\Delta$ ) $\mathrm{mg} / \mathrm{m}^{3}$ eight hour $T W A(Z+E)-D C P$ in respiratory air. Dark shaded areas indicate exposure periods. 
Table 2 Urinary half lives of elimination of thioethers and mercapturic acids of $(Z+E)-D C P$ based on excretion rates $(\mathrm{mg} / \mathrm{h})$ and on creatinine excretion ( $\mathrm{mmol} / \mathrm{mol}$ creatinine) in applicators occupationally exposed to soil fumigants containing $D C P$

\begin{tabular}{lll}
\hline & \multicolumn{1}{l}{$t_{1,2}$ of elimination $(h(S D))$} \\
\cline { 2 - 3 } & $\begin{array}{l}\text { Mercapturic } \\
\text { acids } \dagger\end{array}$ & Thioethers \\
\hline Excretion rate $(\mathrm{n}=5)$ & $4 \cdot 6(1 \cdot 0)$ & $8 \cdot 0(2 \cdot 5)^{\star}$ \\
Creatinine excretion $(\mathrm{n}=9)$ & $4.9(0 \cdot 8)$ & $9 \cdot 5(3 \cdot 1)^{\star \star}$ \\
\hline
\end{tabular}

${ }^{\star} p<0.05 ;{ }^{\star \star} p<0.01$.

+Taken from reference ${ }^{7}$.

with decreasing concentrations of E-DCP-MA, reaching a value of $28 \cdot 5 \%$ at $0 \cdot 10 \mathrm{mmol} / \mathrm{l}$. The high values of the day to day CVs were probably due to variation in the efficiency of the alkaline hydrolysis step in the thioether assay. From day to day the efficiency of the alkaline hydrolysis varied from 60 to $90 \%$. The efficiency of the ethyl acetate extraction of E-DCP-MA was 94.7 (SD 6.6)\%; Z-DCP-MA appeared to have the same recovery in the thioether assay as E-DCP-MA. Therefore, only E-DCP-MA was selected as a reference compound for this study.

\section{BACKGROUND THIOETHER CONCENTRATIONS}

Control urine samples were obtained from four volunteers $(\mathrm{n}=27)$ and 12 applicators $(\mathrm{n}=29)$. Background thioether concentrations were log normally distributed over a range from 1.26 to 16.33 $\mathrm{mmol} \mathrm{SH} / \mathrm{mol}$ creatinine. The mean background was $6.05 \mathrm{mmol} \mathrm{SH} / \mathrm{mol}$ creatinine with a $95 \%$ confidence interval $(95 \% \mathrm{CI})$ lower limit of $5.48 \mathrm{mmol} \mathrm{SH} / \mathrm{mol}$ creatinine and an upper limit of $6.68 \mathrm{mmol} \mathrm{SH} / \mathrm{mol}$ creatinine.

\section{URINARY THIOETHER EXCRETION}

Figure 1 shows the urinary thioether excretion profiles expressed per mol creatinine, of three applicators, exposed to $3 \cdot 8,9 \cdot 8$, and $18.9 \mathrm{mg} / \mathrm{m}^{3}$ eight hours time weighted average (TWA) $(Z+E)-D C P$ respectively. Pre-shift thioether concentrations corresponded with background concentrations of thioethers seen in control urine samples. Thioether excretion increased rapidly after exposure to DCP started and thioether concentrations appeared to be dependent on duration and level of exposure. Maximum thioether concentrations measured at the exposures presented in fig 1 were $16 \cdot 6,27 \cdot 3$, and $48 \cdot 0$ $\mathrm{mmol} \mathrm{SH} / \mathrm{mol}$ creatinine respectively.

Post-shift urinary excretion of thioethers followed first order elimination kinetics. Urinary elimination rate constants were calculated if the correlation coefficients of the semilog linear parts of the excretion $v$ time curves were $r \geq 0.917$ and if at least four postshift data points with $\mathrm{SH}$ concentrations higher than the background excretion levels, observed in con-

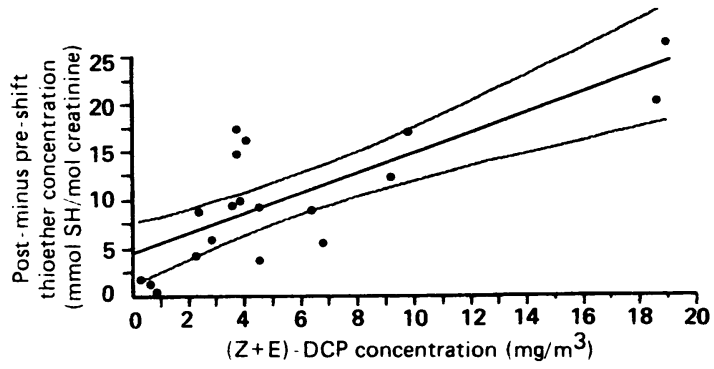

Figure 2 Correlation between eight hour $T W A(Z+E)-$ $D C P$ concentration in respiratory air and urinary post-minus pre-shift thioether concentrations in applicators. Regression line $y=4.37+1.05 x(r=0.79 ; n=19 ; p=0.001)$ and $95 \%$ CIs are drawn.

trols, were available. Urinary elimination rate constants were used to calculate $t_{1 / 2}$ of elimination. Only a few excretion profiles met all these requirements, primarily due to background excretion of thioethers. The $t_{1 / 2}$ of elimination was calculated both from excretion rates and creatinine excretion. Based on excretion rates, half lives of elimination were 9.8, $8 \cdot 1$, and 9.7 hours, respectively (fig 1). Mean $t_{1 / 2}$ of elimination based on excretion rates was 8.0 (SD 2.5) hours $(n=5)$ and based on creatinine excretion 9.5 (SD $3 \cdot 1$ ) hours $(\mathbf{n}=9)$. A roughly twofold larger statistically significant difference $(p<0.05)$ in $t_{1 / 2}$ of elimination of thioethers was seen when compared with the urinary $t_{1 / 2}$ of elimination of mercapturic acids determined previously (table 2 ).

THIOETHER EXCRETION IN RELATION TO DCP EXPOSURE Figure 2 shows the relation between the eight hour TWA exposure to $(Z+E)-D C P$ and the thioether concentration, expressed per mol creatinine, of the first urine sample collected post-shift minus the thioether concentration of the sample collected preshift. Subtraction of the pre-shift thioether concentration served as an individual correction of the

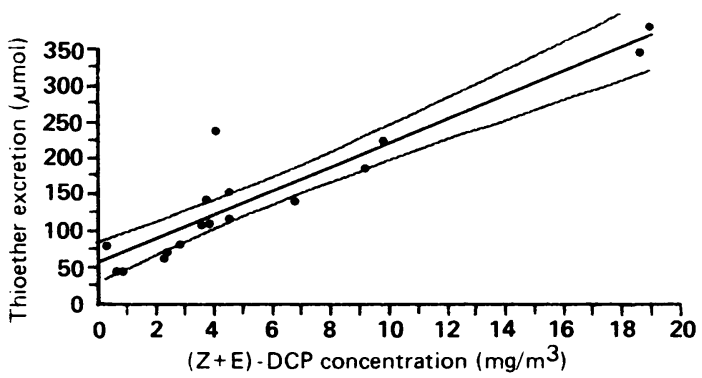

Figure 3 Correlation between eight hour $T W A(Z+E)$ $D C P$ concentration in respiratory air and cumulative urinary thioether excretion in applicators. Regression line $y=56.5+16.5 x(r=0.93 ; n=17 ; p<0.001)$ and $95 \%$ CIs are drawn. 


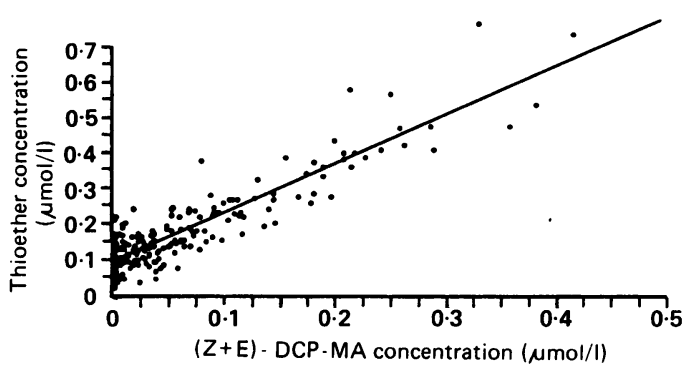

Figure 4 Correlation between $(Z+E) D C P-M A$ concentration and thioether concentration in urine samples of applicators. Regression line $y=0.09+1.38 x(r=0.90$; $n=221 ; p<0.001)$ is drawn.

background thioether excretion and improved the correlation with exposure to DCP. The correlation coefficient between DCP exposure and post- minus pre-shift thioether concentration was $\mathrm{r}=0.79$.

Figure 3 shows the relation between the eight hour TWA exposure to $(Z+E)-D C P$ and the cumulative thioether excretion in urine. Cumulative excretion of thioethers was calculated as the area under the urinary thioether excretion rate $v$ time curve (AUC) from the start of the shift until eight hours post-shift. Data for two applicators were omitted; one applicator wore a respirator and the excretion curve of the other was too irregular to interpret. A correlation coefficient of $r=0.93$ was found between exposure to DCP and cumulative excretion of thioethers in urine.

\section{COMPARISON OF THIOETHER AND MERCAPTURIC ACID} EXCRETION

In a previous study, ${ }^{7}$ concentrations of $\mathrm{Z}$ - and E-DCP-MA were determined in the same urine samples in which the presently reported thioether concentrations were measured. Figure 4 shows the relation between $(Z+E)$-DCP-MA concentrations and the thioether concentrations. Urine samples in which no mercapturic acids were detected and samples in which the thioether concentration was in the

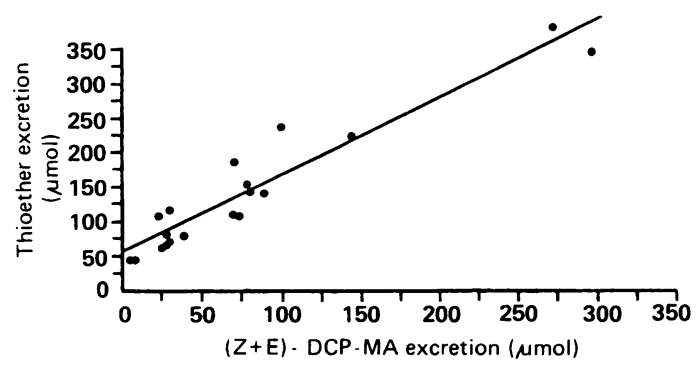

Figure 5 Correlation between cumulative urinary $Z+E)-D C P-M A$ excretion and cumulative urinary thioether excretion. Regression line $y=56.48+1 \cdot 11 x$ $(r=0.95 ; n=19 ; p<0.001)$ is drawn. range of the background level ( $\leq 6.68 \mathrm{mmol} \mathrm{SH} / \mathrm{mol}$ creatinine), were omitted from the regression analysis. The regression line was $\mathrm{y}=0.09+1.38 x$ $(r=0.90)$.

Figure 5 compares the cumulative urinary excretion of $(Z+E)$-DCP-MA and of thioethers, both calculated as the area under the excretion rate $v$ time curves, for 19 shifts. Cumulative excretion of the thioethers was calculated from the start of the shift until eight hours post-shift. Cumulative excretion of mercapturic acid was also calculated from the start of shift. Terminal excretion, however, was calculated by extrapolating time to infinity using the elimination rate constant. ${ }^{7}$ The regression line was $\mathrm{y}=56.48+$ $1 \cdot 11 x(\mathrm{r}=0.95)$.

\section{Discussion}

In this study, the excretion of thioethers in urine of applicators of DCP was investigated in relation to the exposure to this soil fumigant. Urinary half lives of elimination of thioethers were calculated, and thioether and mercapturic acid excretion were compared. Also, the thioether assay was evaluated quantitatively.

At present, no data concerning extraction recoveries and detection limits of thioethers in the thioether assay are available. N-acetyl-S-(E-3chloropropenyl-2-)-L-cysteine (E-DCP-MA), a mercapturic acid metabolite of E-DCP, was therefore used as a synthetic standard to evaluate the analytical performance of the thioether assay. Standard calibration curves of $\mathrm{SH}$ groups and calibration curves of thioethers in human urine all showed good linearity. The recovery of E-DCP-MA from human urine was only $58.5 \%(\mathrm{CV}=9 \%, \mathrm{n}=$ 4) but did not differ significantly day to day. The within day recovery $C V$ remained below $6.6 \%$ for $E$ DCP-MA concentrations ranging from $0 \cdot 10$ to $0 \cdot 80$ $\mathrm{mmol} / \mathrm{l}$ urine. Day to day recovery CV of E-DCP$\mathrm{MA}$, however, amounted to $28.5 \%$ at $0 \cdot 10 \mathrm{mmol} / 1$ E-DCP-MA, stressing the need for preparing calibration curves daily. The detection limit of EDCP-MA in the thioether assay was $0.10 \mathrm{mmol} / \mathrm{l}$. Lower concentrations could be detected as thioether but the CV exceeded $10 \%$. Previously, recoveries of $\mathrm{Z}$ - and E-DCP-MA from urine were found to be $69 \%(C V=7 \%, n=4)$ and $70 \%(C V=8 \%, n=4)$ when measured by gas chromatography. With this technique, detection limits of Z- and E-DCP-MA were $0.45 \mu \mathrm{mol} / 1(\mathrm{CV}=7 \cdot 2 \%, \mathrm{n}=8){ }^{5}$

In urine samples obtained from non-exposed volunteers and applicators, a mean thioether background of $6.05 \mathrm{mmol} \mathrm{SH} / \mathrm{mol}$ creatinine was found. Comparable background concentrations ranging from 3.8 to $5.1 \mathrm{mmol} \mathrm{SH} / \mathrm{mol}$ creatinine were found previously in other reference populations. ${ }^{41}$ Smoking, medication, and other confounding factors 
of lifestyle were not taken into account in our present study. None of the subjects was taking medicines, however, and only four of 12 applicators were moderate smokers. Moderate smoking did not result in significantly increased urinary excretion of thioether in the group of non-exposed volunteers.

The shapes of the urinary thioether excretion profiles appeared to be similar at different exposures in the applicators. As already found with $\mathrm{Z}$ - and E-DCP-MA excretion, thioether excretion rapidly increased after exposure to DCP started and followed first order excretion kinetics. The height of thioether excretion depended on the level and duration of exposure. Pre-exposure and, in general, more than eight hours post-exposure, normal background excretion concentrations of thioethers were seen in applicators.

Urinary $t_{1,2}$ values for elimination of thioethers were $8.0($ SD 2.5) hours and 9.5 (SD 3.1) hours based on excretion rates or on creatinine excretions, respectively. Compared with the $t_{1 / 2}$ of elimination of the mercapturic acids of DCP, $t_{1 / 2}$ of elimination of thioethers was almost twice as high. This significant difference can be explained by the presence of a (DCP) thioether metabolite(s) with a longer $t_{1 / 2}$ of elimination than those of $(Z+E)-D C P-M A$. Exposure to impurities in commercial DCP formulations could be the reason for differences between urinary thioether excretion and urinary mercapturic acid excretion.

Two urinary thioether excretion parametersnamely, post- minus pre-shift thioether concentration and cumulative thioether excretion-proved to be successful in assessing exposure to DCP. Both parameters showed good linear relations with exposure to DCP. Cumulative Z- and E-DCPMA excretion also correlated well with exposure to DCP. ${ }^{7}$ In line with both findings, thioether and mercapturic acid concentrations in urine samples of applicators showed a strong linear relation. The intercept of the regression equation corresponded to thioether concentrations found in blank urine samples. The slope of 1.38 supported the postulated presence of an unidentified thioether metabolite(s). Cumulative thioether excretion also exceeded cumulative mercapturic acid excretion. In calculating the first, however, no corrections were made for the background excretion and in calculating the second, excretion to infinity was taken into consideration.

The question remains at which DCP exposures the mercapturic acid and thioether assay can be applied successfully. The determination of the mercapturic acids of DCP by gas chromatography with different detection techniques proved to be much more sensitive and selective than the determination of thioethers with the thioether assay. Moreover, the mercapturic acids of DCP were not detectable in urine of subjects not exposed to this soil fumigant. Exposure to $<0.09 \mathrm{mg} / \mathrm{m}^{3}$ (eight hour TWA) for 4.9 hours, however, resulted in detectable Z-DCP-MA concentrations in urine of volunteers. By contrast, thioethers are excreted with background concentrations depending on lifestyle. The upper limits of the $95 \% \mathrm{CI}$ of the intercepts of the post-minus pre-shift concentrations $(7.5 \mathrm{mmol} \mathrm{SH} / \mathrm{mol}$ creatinine) and the cumulative excretion ( $88 \mu \mathrm{mol} \mathrm{SH}$ ) indicate the increments in thioether excretion that are necessary to distinguish between samples from exposed and non-exposed subjects. According to the respective regression equations $7.5 \mathrm{mmol} \mathrm{SH} / \mathrm{mol}$ creatinine corresponded to an eight hour TWA exposure of 3.0 $\mathrm{mg} / \mathrm{m}^{3} \mathrm{DCP}$ and $88 \mu \mathrm{mol} \mathrm{SH}$ to an eight hour TWA exposure of $1.9 \mathrm{mg} / \mathrm{m}^{3} \mathrm{DCP}$. The thioether assay can be used to assess comparatively high DCP exposure levels.

An eight hour TWA exposure to the Dutch occupational exposure limit of $5 \mathrm{mg} / \mathrm{m}^{3} \mathrm{DCP}$ would result in a post-minus pre-shift thioether concentration of $9.6 \mathrm{mmol} \mathrm{SH} / \mathrm{mol}$ creatinine with a $95 \% \mathrm{CI}$ of 7.4 to $11.8 \mathrm{mmol} \mathrm{SH} / \mathrm{mol}$ creatinine. The same exposure level would result in an excretion of 139 $\mu \mathrm{mol} \mathrm{SH}$ with a $95 \%$ CI of 120 to $157 \mu \mathrm{mol} \mathrm{SH}$. These values could regarded as warning limits to be used by occupational hygienists.

This investigation was financially supported by the Directorate General of Labour of the Ministry of Social Affairs and Employment and the Ministry of Housing, Physical Planning, and the Environment.

Requests for reprints to: N P E Vermeulen, Department of Pharmacochemistry, Division of Molecular Toxicology, Free University, De Boelelaan 1083, 1081 HV Amsterdam, The Netherlands.

1 Doorn van $R$, Leijdekkers Ch-M, Bos RP, Brouns RME, Henderson PTh. Detection of human exposure to electrophilic compounds by assay of thioether detoxication products in urine. Ann Occup Hyg 1981;24:77-92.

2 Kilpikari I. Correlation of urinary thioethers with chemical exposure in a rubber plant. Br J Ind Med 1981;38:98-100.

3 Ahlborg G, Bergström B, Hogstedt C, Einistö P, Sorsa $M$. Urinary screening for potentially genotoxic exposures in a chemical industry. Br $J$ Ind Med 1985;42:691-9.

4 Burgaz S, Bayhan A, Karakaya AE. Thioether excretion of workers exposed to bitumen fumes. Int Arch Occup Environ Health 1988;60:347-9.

5 Welie van RTH, Duyn van P, Vermeulen NPE. Determination of two mercapturic acid metabolites of 1,3-dichloropropene in human urine with gas chromatography and sulphur-selective detection. J Chrom Biomed Appl 1989;496:463-71.

6 Vermeulen NPE. Analysis of mercapturic acids as a tool in biotransformation, biomonitoring and toxicological studies. Tips 1989;10:177-81.

7 Welie van RTH, Duyn van P, Brouwer DH, Hemmen van JJ, Brouwer EJ, Vermeulen NPE. Inhalation exposure to 1,3dichloropropene in the Dutch flower-bulb culture. Part II. Biological monitoring by measurement of urinary excretion of two mercapturic acid metabolites. Arch Environ Contam Toxicol 1991;20:6-12. 
8 Onkenhout W, Mulder PPJ, Boogaard PJ, Buijs W, Vermeulen NPE. Identification and quantitative determination of mercapturic acids formed from Z-and E-1,3-dichloropropene by the rat, using gas chromatography with three different detection techniques. Arch Toxicol 1986;59:235-41.

9 Brouwer DH, Brouwer EJ, Vreede de JAF, Welie van RTH, Vermeulen NPE, Hemmen van JJ. Inhalation exposure to 1,3dichloropropene in the Dutch flower-bulb culture. Part I. Environmental monitoring. Arch Environ Contam Toxicol 1991;20:1-5.

10 Brouwer EJ, Evelo CIA, Verplanke AJW, Welie van RTH, Wolff de FA. Biological effect monitoring of occupational exposure to 1,3-dichloropropene: effects on liver and renal function and on glutathione conjugation. Br J Ind Med 1991;48:167-72.

11 Doorn van R, Leijdekkers Ch-M, Bos RP, Brouns RME Henderson PTh. Enhanced excretion of thioethers in urine of operators of chemical waste incinerators. $\mathrm{Br} J$ Ind $\mathrm{Med}$ 1981;38:187-90.

12 Ellman GI. Tissue sulfhydryl groups. Arch Biochem Biophys 1959;82:70-7.

13 Tietz NW. Textbook of clinical chemistry. Philadelphia: WB Saunders, 1986:1279.

Accepted 26 November 1990
All manuscripts submitted to the $B r J$ Ind Med should conform to the uniform requirements for manuscripts submitted to biomedical journals (known as the Vancouver style).

The $\mathrm{Br} J$ Ind Med, together with many other international biomedical journals, has agreed to accept articles prepared in accordance with the Vancouver style. The style (described in full in $\mathrm{Br}$ Med J, 24 February 1979, p 532) is intended to standardise requirements for authors.

References should be numbered consecutively in the order in which they are first mentioned in the text by Arabic numerals above the line on each occasion the reference is cited (Manson ${ }^{1}$ confirmed other reports ${ }^{2-5} \ldots$... In future references to papers submitted to the $\mathrm{Br} J$ Ind Med should include: the names of all authors if there are six or less or, if there are more, the first three followed by et al; the title of journal articles or book chapters; the titles of journals abbreviated according to the style of Index Medicus; and the first and final page numbers of the article or chapter.

Examples of common forms of references are:

1 International Steering Committee of Medical Editors. Uniform requirements for manuscripts submitted to biomedical journals. Br Med J 1979;1:532-5.

2 Soter NA, Wasserman SI, Austen KF. Cold urticaria: release into the circulation of histamine and eosino-phil chemotactic factor of anaphylaxis during cold challenge. N Engl J Med 1976;294:687--90.

3 Weinstein L, Swartz MN. Pathogenic properties of invading micro-organisms. In: Sodeman WA Jr, Sodeman $W A$, eds. Pathologic physiology: mechanisms of disease. Philadelphia: W B Saunders, 1974:457-72. 